\title{
PANORAMA DA COLETA SELETIVA EM PRESIDENTE PRUDENTE: DESAFIOS E PERSPECTIVAS
}

Lucas Nascimento Zulli - lucas.zulli.unoeste@ outlook.com

Universidade do Oeste Paulista - UNOESTE

Nelissa Garcia Balarim - nelissa@ unoeste.br

Universidade do Oeste Paulista - UNOESTE

Janardelly Gomes de Souza - janardelly.jgs@ gmail.com

Universidade do Oeste Paulista - UNOESTE

Wesley Roberto Soares Pinto - wesley.soares1x@ live.com

Universidade do Oeste Paulista - UNOESTE 


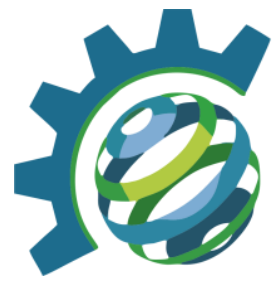

\section{RESUMO}

A coleta seletiva é uma das principais etapas do gerenciamento dos resíduos sólidos, pois a partir dela é possível viabilizar a reciclagem ou reutilização dos materiais desenvolvendo a cadeia produtiva reversa sustentável. Além disto, a coleta evita a poluição do meio ambiente (água, solo e ar), aumenta a vida útil dos aterros e promove a geração de empregos.

A fim de atender às recomendações da Política Nacional de Resíduos Sólidos - Lei Federal $\mathrm{n}^{\circ} 12.305 / 2010$, o município de Presidente Prudente possui programa de coleta seletiva porta-em-porta que é realizado por uma cooperativa de catadores chamada COOPERLIX - Cooperativa de Trabalhadores de Produtos Recicláveis de Presidente Prudente. No entanto, existem diversos desafios a serem superados pelo setor como: atendimento regular a população, melhoria da infraestrutura e sistema logístico.

Nesse sentido, o presente trabalho tem como objetivo analisar o programa de coleta seletiva em Presidente Prudente e propor melhorias ao sistema a fim de garantir um serviço de qualidade à população. O desenvolvimento do trabalho consistiu na análise das rotas dos GPS dos caminhões da coleta, reuniões com os cooperados e elaboração de novos mapas de rotas da coleta.

Palavras-chave: Coleta seletiva, resíduos sólidos, cooperativas, reciclagem.

\section{INTRODUÇÃO/OBJETIVO}

A crescente geração dos resíduos é proveniente principalmente do consumo elevado da população, que se dá pela facilidade de acesso a produtos e assim aumento da demanda por insumos e problemas com a disposição final destes resíduos.

O município de Presidente Prudente, localizado na região sudoeste do estado de São Paulo possui uma área de 560, $637 \mathrm{~km}^{2}$ com uma população aproximadamente de 223.749 habitantes (IBGE,2016). A cidade conta com um plano de gerenciamento municipal, que traz uma estimativa de geração de resíduos domiciliares de $1,08 \mathrm{~kg} / \mathrm{hab} /$ dia.

Parte desses resíduos é coletado pela cooperativa (COOPERLIX), que desde 2015 possui contrato com a prefeitura, que garante o pagamento mensal aos cooperados pelos serviços ambientais de coleta e triagem de material reciclável.

A cooperativa tem 90 funcionários e conta com uma infraestrutura que se compõe por prédio próprio, esteiras, prensas hidráulicas e utiliza 5 caminhões para a coleta.

Desta forma, atualmente a coleta seletiva no município é realizada de segunda a sexta e está estruturada em 25 setores, sendo que diariamente são realizados em 5 setores. No entanto o sistema apresenta alguns problemas relacionados a extensão do município e setores com grandes áreas ou com geração elevada de resíduos.

Como um dos problemas mais recorrentes refere-se ao sistema logístico, no início deste ano, foi adquirido um caminhão gaiola para ajudar na coleta, e assim se faz necessário um redimensionamento dos setores

Justificando assim o desenvolvimento do presente trabalho, que é propor o redimensionamento da coleta por meio de uma nova divisão dos setores de forma a abrigar o novo caminhão e assim garantir a melhoria do serviço. 

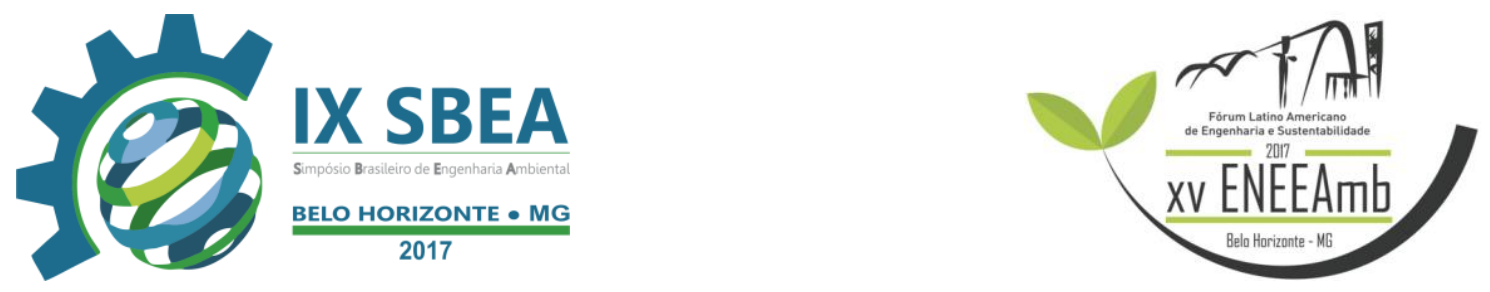

\section{METODOLOGIA}

\section{Área de Estudo}

O estudo foi realizado no município de Presidente Prudente - SP (Figura 01) que é uma cidade de porte médio e possui cerca de 223.749 habitantes (IBGE, 2016), a mesma dispõe de uma área territorial de $560,637 \mathrm{~km}^{2}$ e uma densidade demográfica 368,89 hab. $/ \mathrm{km}^{2}$ localizando-se ao sul do Oeste Paulista.

Figura 01 - Localização do Município de Presidente Prudente-SP

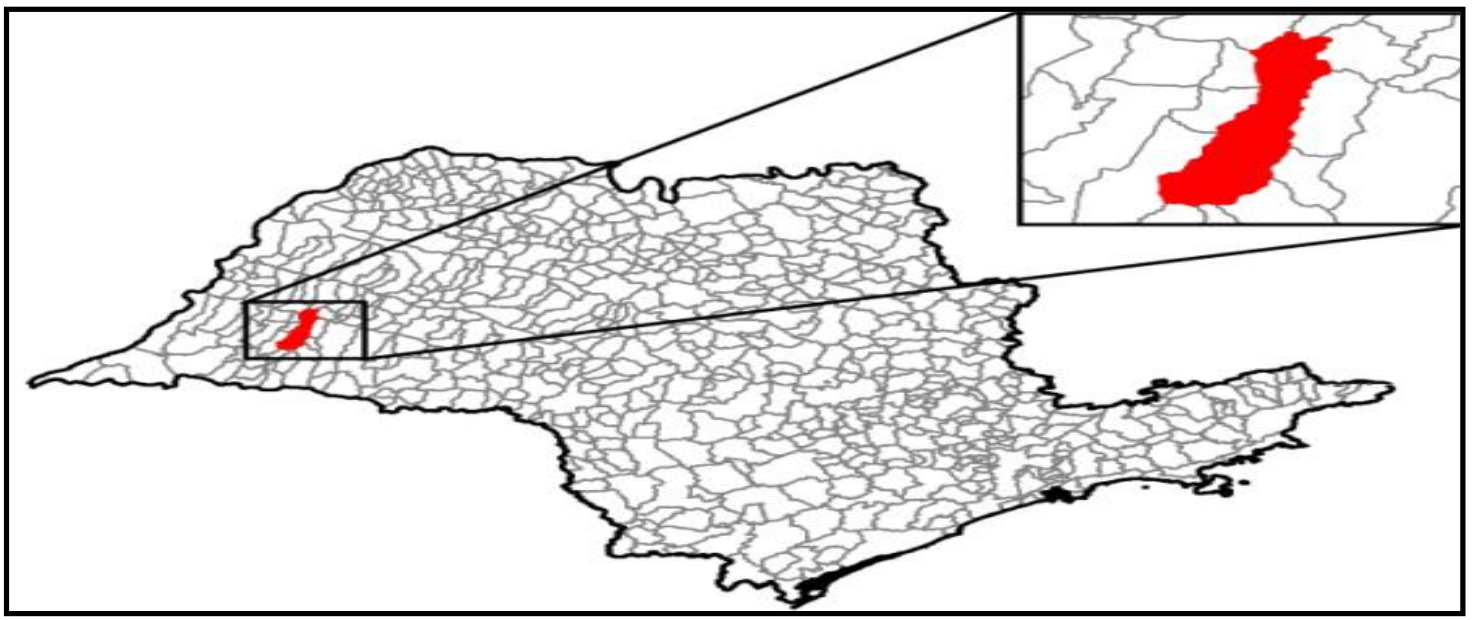

Fonte: IPT, 2015 adaptado em, 2017.

\section{Etapas de trabalho}

O desenvolvimento do estudo foi conduzido durante um período de 30 dias, sendo divido em seis etapas (Figura 02): Etapa I - Análise do mapa da coleta seletiva em vigência; etapa II - Aquisição dos dados do GPS das rotas percorridas pelos caminhões da coleta; etapa III - Análise dos registros do GPS; etapa IV - Elaboração do mapa das áreas coletadas mensalmente pelos caminhões e o cálculo das médias; etapa V - Reunião com a COOPERLIX; etapa VI - Elaboração do mapa com a nova setorização.

As primeiras etapas foram à junção dos dados já existentes que contribuíram para elaboração do mapa e cálculos com as médias mensais de coleta, logo após buscou-se por intermédio das reuniões um ponto de vista profissional dos cooperados para que assim chegasse à etapa final, que foi a proposição de uma nova setorização levando em consideração os setores que apresentavam maior dificuldade na coleta. Abaixo segue o fluxograma das etapas de trabalho. 


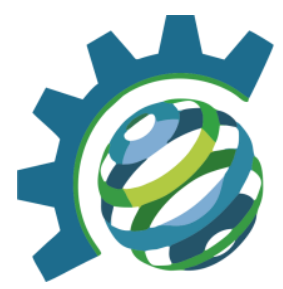

Figura 02 - Fluxograma das etapas de trabalho

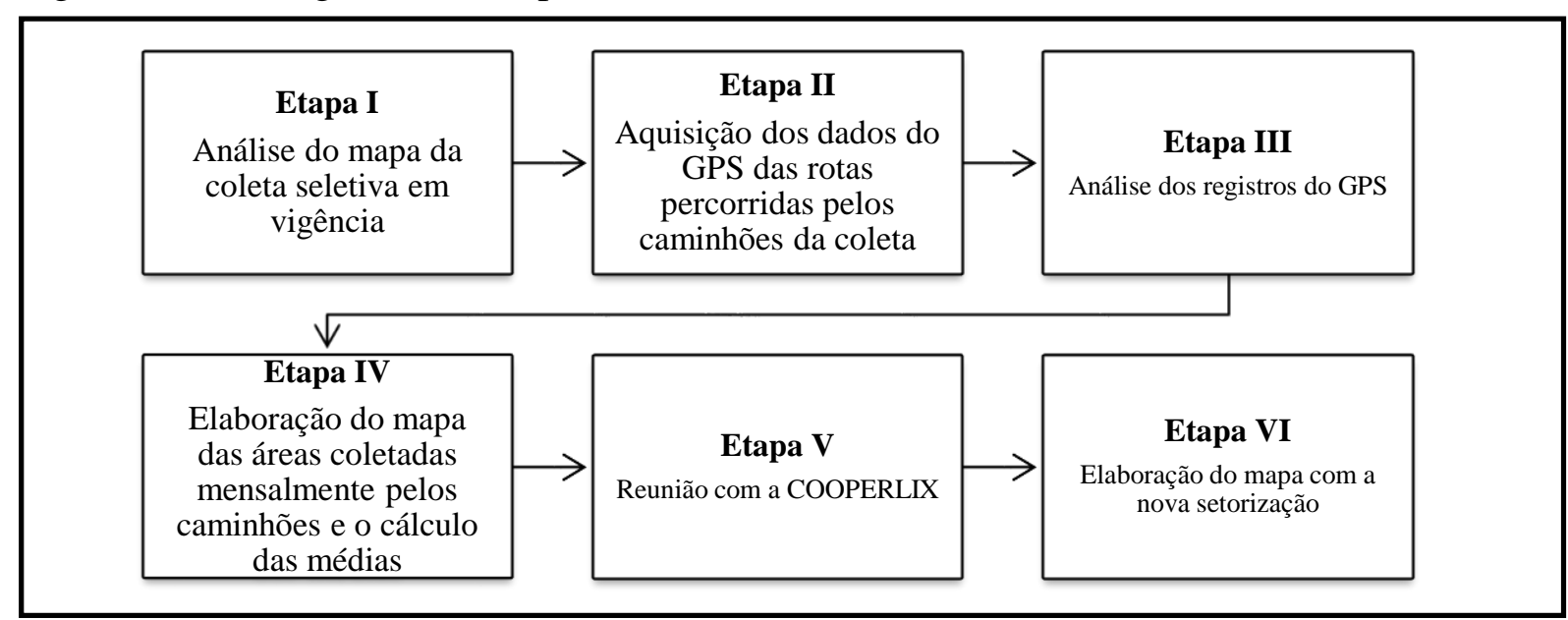

- Etapa I: Consistiu-se na análise do mapa com a divisão dos setores da coleta seletiva ordenados através de um padrão de cores, representando assim cada dia da semana e com isso observou-se a distribuição dos mesmos;

- Etapa II: a aquisição dos dados deu-se a partir de um GPS instalado nos caminhões, configurado com o aplicativo GR Tracker que registra o percurso percorrido pelos caminhões e transmite para o software que grava este caminho que depois é enviado e armazenado automaticamente em um computador;

- Etapa III: na análise dos registros do GPS levou-se em consideração as áreas onde os caminhões tiveram maior ocorrência dentro de seus respectivos setores, de forma que se realizou um comparativo visual dos dados semanais em um período de 30 dias;

- Etapa IV: com base no comparativo dos dados anteriores elaborou-se um novo mapa com as áreas onde os caminhões realizavam seu trajeto com maior frequência, através da ferramenta AutoCAD versão 2013 e as informações encontradas foram calculadas com base na área total dos setores e área total coleta, utilizando a equação da regra de 3, ou seja, "((área coletada x 100)/ área total)", assim sendo encontrado a porcentagem de coleta com o auxílio da ferramenta EXCEL 2013;

- Etapa V: no dia 24 de abril de 2017 realizou-se a reunião com os cooperados responsáveis pela COOPERLIX, sendo apresentados os requisitos para a elaboração do novo;

- Etapa VI: após o parecer dos representantes da cooperativa houve o redimensionamento dos setores e a elaboração de um novo mapa com cinco setores a mais, isso foi realizado através da ferramenta AutoCAD versão 2013 estudante.

\section{RESULTADOS E DISCUSSÃO}

A COOPERLIX que é a responsável pela coleta seletiva da cidade recolhe cerca de 200 ton./mês de material reciclável, sendo assim atualmente a coleta em Presidente PrudenteSP é composta por 25 setores. A Figura 03 apresenta a distribuição dos 25 setores, de forma que cada dia da semana tem sua cor representativa como mostrado na legenda. 

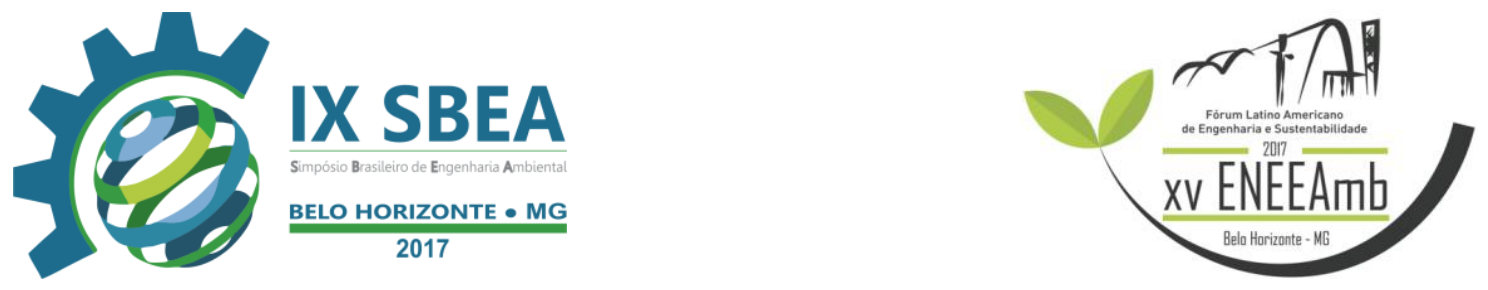

Figura 03 - Mapa da divisão dos setores da coleta seletiva no ano de 2015

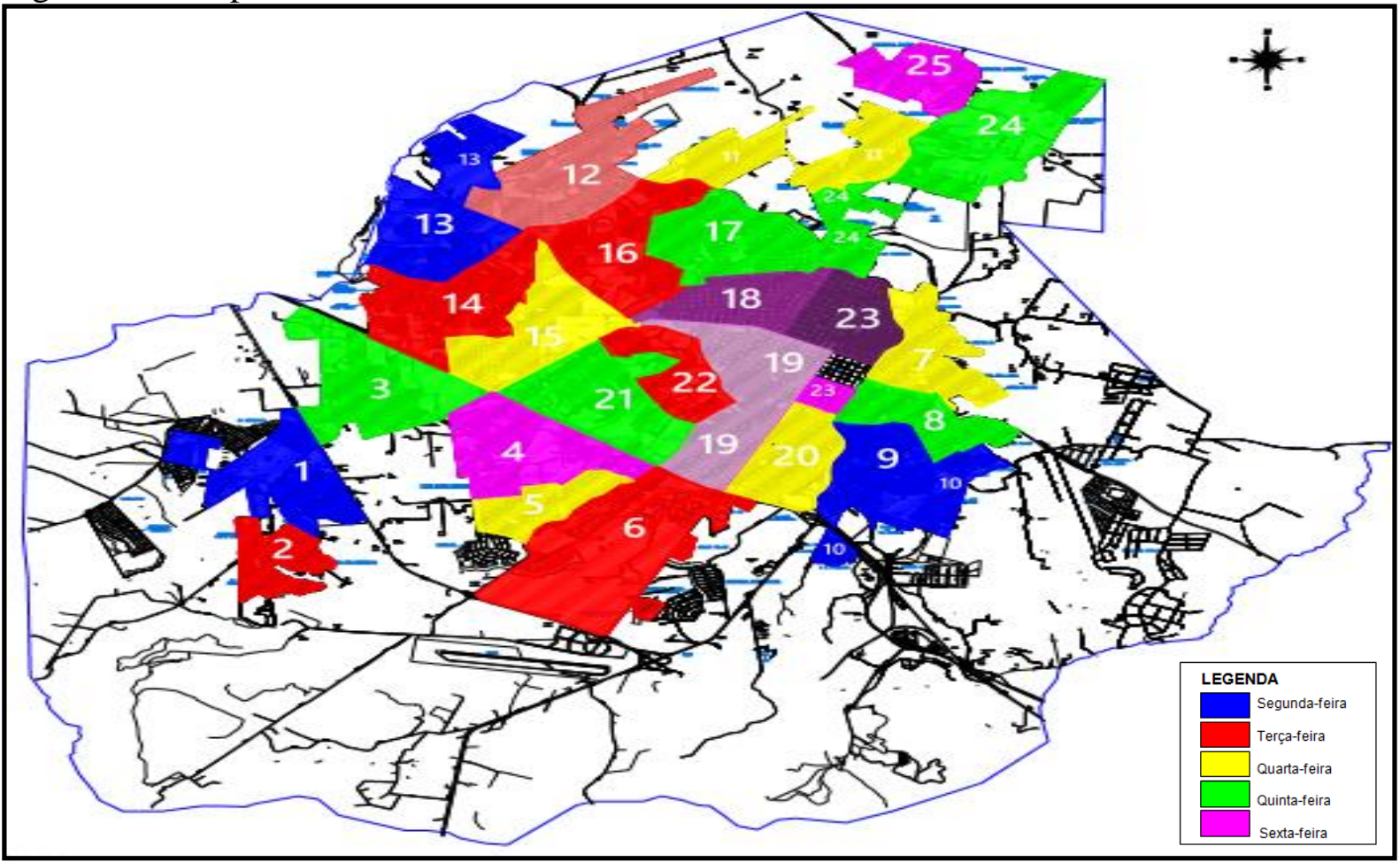

As rotas são percorridas semanalmente nesses setores pelos caminhões, porém existe uma ineficiência que ocorre devido ao fato de alguns setores apresentarem área grande, problemas relacionados aos caminhões e longas distâncias percorridas.

A Figura 04 apresenta um exemplo das rotas realizadas pelo caminhão no setor 09 , que foi obtido através do GPS acoplado no caminhão, assim os pontos verdes indicam que a rota está sendo efetuada no setor correto e vermelho quando a mesma se encontra fora do setor.

Pode-se observar que a coleta não é realizada em todo setor, não atendendo parte da população. 

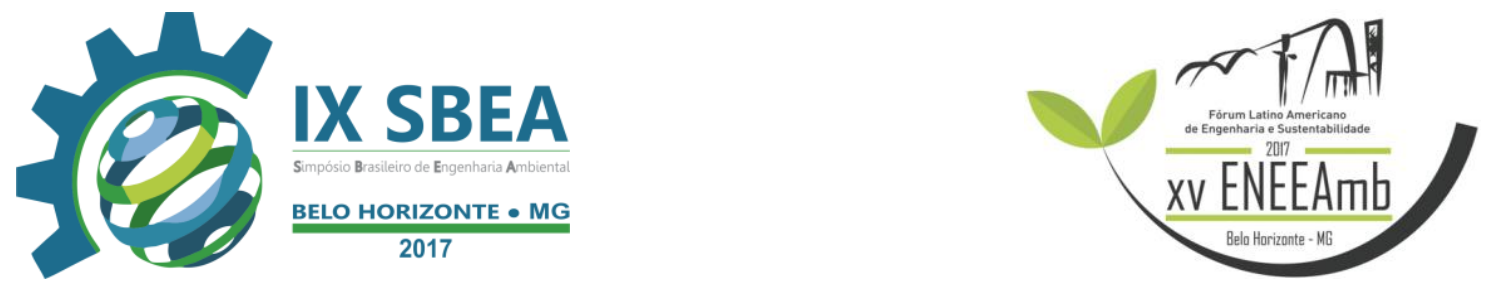

Figura 04 - Exemplo do percurso da coleta no setor 09

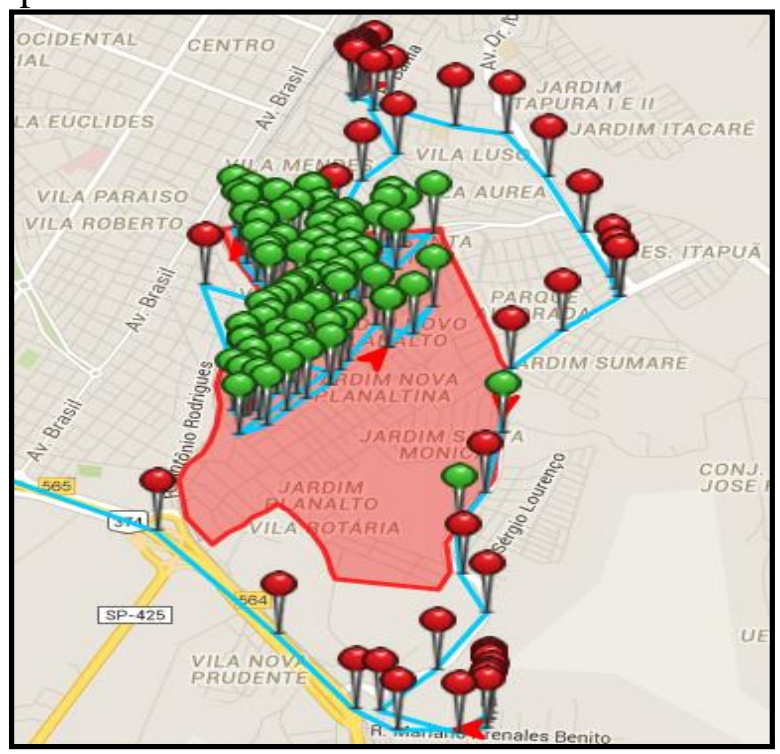

Com base nos dados de todos os setores obtidos durante um período de 30 dias, foi realizado um comparativo visual dos trajetos percorridos pelos caminhões da coleta e com isso, elaborou-se um mapa com as médias das rotas mensais das quais foram destacadas em vermelha (Figura 05). Após a identificação das áreas, foi feita uma relação com o tamanho de seu setor e o valor correspondente a porcentagem coletada (Quadro 01), para que obtivesse os parâmetros dos setores e assim fosse observado quais os setores que apresentavam maior ineficiência. A partir disso, os dados obtidos foram apresentados em reunião com a participação dos cooperados.

Quadro 01 - Porcentagem coletada em relação a área total dos setores

\begin{tabular}{|c|c|c|}
\hline $\begin{array}{c}\text { Área total dos setores } \\
\left(\mathbf{K m}^{\mathbf{2}}\right)\end{array}$ & $\begin{array}{c}\text { Área total coletas } \\
\left(\mathbf{K m}^{\mathbf{2}}\right)\end{array}$ & $\begin{array}{c}\text { Porcentagem coletada } \\
\mathbf{( \% )}\end{array}$ \\
\hline 51,24 & 13,57 & 26,48 \\
\hline
\end{tabular}





Figura 05 - Média das rotas mensais das coletas realizadas pelos caminhões



Com a elaboração do mapa com a média das rotas mensais (Figura 05) e a realização dos cálculos (Quadro 01) que demonstrou uma relação da área total e área coleta, assim apresentando um baixo índice de coleta, observando-se a necessidade de realizar uma reunião (Figura 06), da qual ocorreu com os três principais representantes da COOPERLIX, onde foram expostos os cinco setores mais caóticos com base em dados analisados, dos quais tiveram como critério a distância e a grande geração de resíduos. Após a apresentação dos problemas, foram discutidas as formas de possíveis soluções para assim serem elaboradas as novas rotas dos caminhões de coleta, sendo levado em consideração a experiência diária de trabalhos dos cooperados. 



Figura 06 - Reunião com os cooperados da COOPERLIX

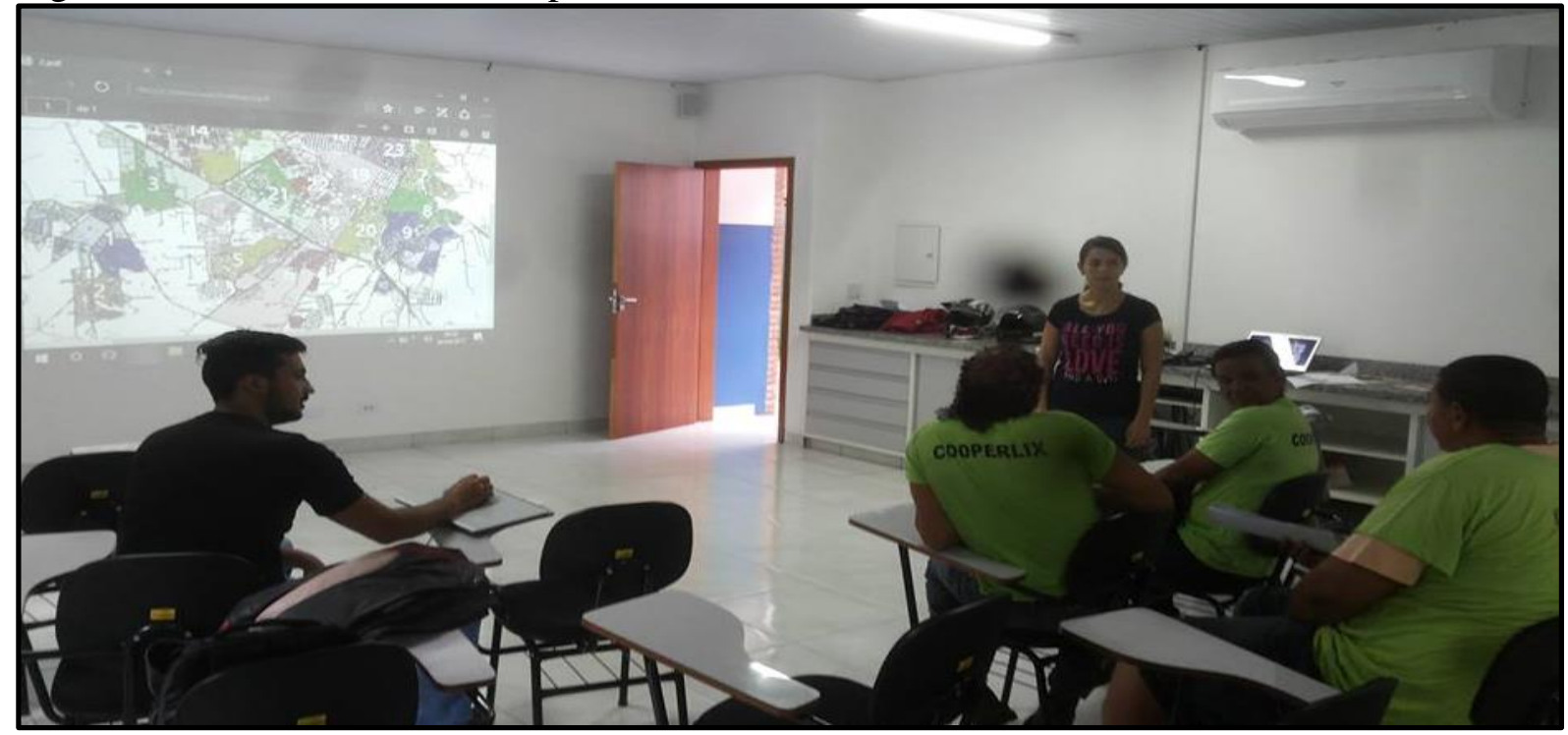

A realização deste último mapa das rotas deu-se após a reunião com os representantes da COOPERLIX, de forma que o redimensionamento dos setores foi elaborado visando atender as áreas mais críticas sendo as que apresentavam maiores áreas, maior distância e geração com a adição do novo caminhão.

A Figura 07 demonstra como ficará a divisão dos setores para a coleta seletiva no município de Presidente Prudente - SP, sendo que os setores mais caóticos foram divididos e deram origem a cinco novos setores, passando assim de 25 para 30.

Figura 07 - Proposta do redimensionamento dos setores

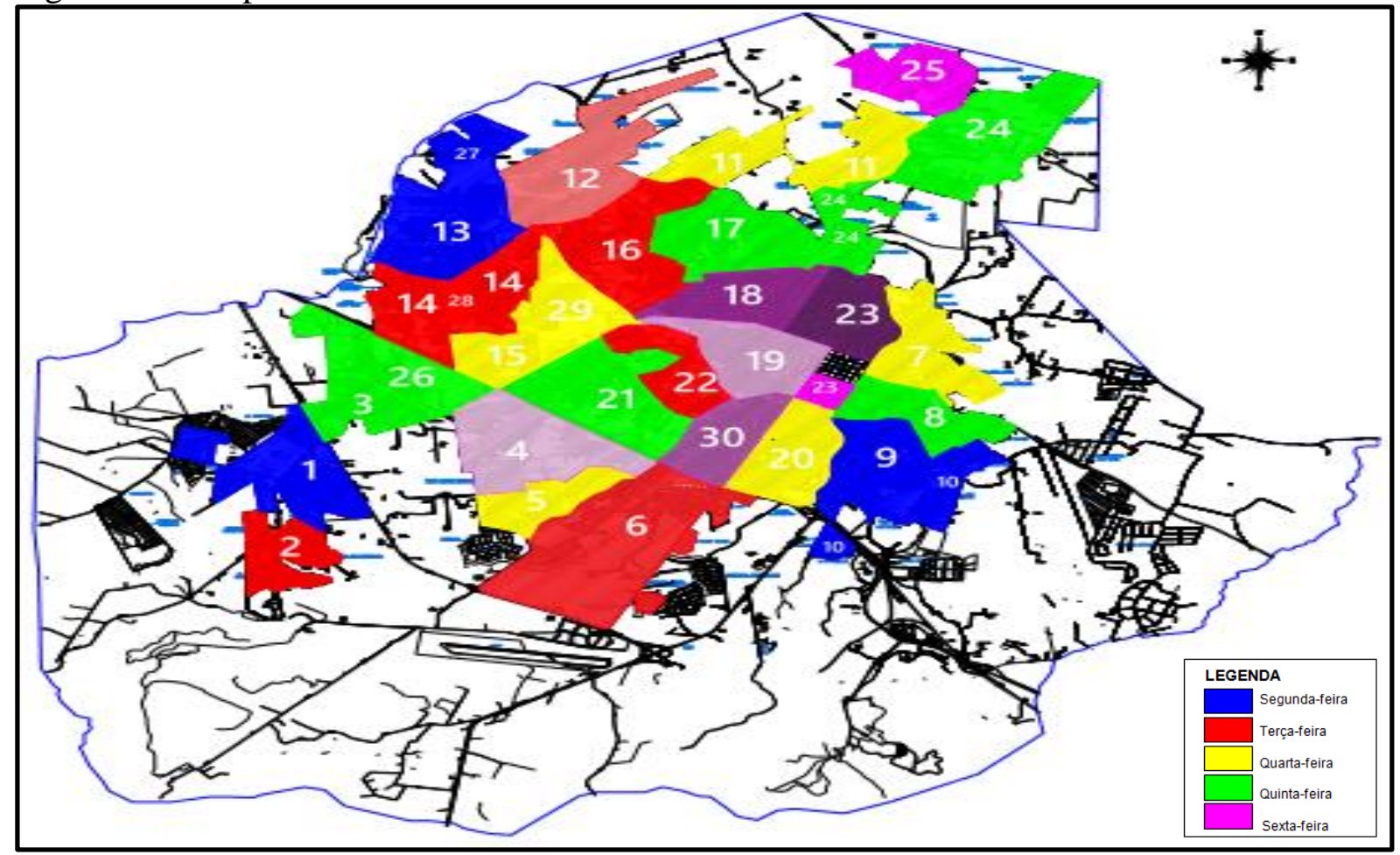

IX Simpósio Brasileiro de Engenharia Ambiental, XV Encontro Nacional de Estudantes de 



\section{CONCLUSÕES/RECOMENDAÇÕES}

Com o levantamento dos dados mediante as algumas etapas do estudo que consistem basicamente na análise do mapa da coleta seletiva em vigência; na aquisição dos dados do GPS das rotas percorridas pelos caminhões da coleta; na análise dos registros do GPS; conclui-se que a coleta seletiva em Presidente Prudente-SP passa por alguns problemas logísticos, isso se dá devido ao tamanho dos setores e também devido à quantidade de caminhões destinados a coleta seletiva.

Quando realizou-se a elaboração final do mapa das áreas coletadas mensalmente pelos caminhões mediante a experiência dos cooperados, como foi explicado no capitulo anterior, buscou-se uma forma de resolver este problema logístico, pois com a proposta de adição de um caminhão para ajudar na coleta seletiva do município juntamente com o redimensionamento das rotas nos setores espera-se que contribua de maneira positiva para o município, no que tange a melhoria da coleta para a população.

\section{REFERÊNCIAS BIBLIOGRÁFICAS}

ADEDIPE N. O. et al. Waste management, processing, and detoxification. In: CHOPRA, K. et al. (Ed.) Millennium Ecosystems Assessment. Ecosystems and Human WellBeing: Policy Responses: findings of the Responses Working Group. Washington, DC: Island Press, 2005. v.3, p.313-34.

BESEN, G. R. et al. Resíduos sólidos: vulnerabilidades e perspectivas. In: SALDIVA P.et al. Meio ambiente e saúde: o desafio das metrópoles. São Paulo: Ex Libris,2010.

BRASIL. Lei n 12.305, de 2 de Agosto de 2010.

IBGE - Instituto Brasileiro de Geografia e Estatística. 2016. Disponível em: http://cod.ibge.gov.br/10I2. Acesso em: 24 abr. 2017.

KLUNDER, A. et al. Concept of ISWM. Gouda: Waste, 2001. 